\title{
Semantic Integration Evaluation Scale (SIS) for Children with Autism Spectrum Disorder
}

\section{Manuel Ojea Rua* and Fernando Tellado González}

Faculty of Education Sciences, Spain

*Corresponding author: Manuel Ojea Rúa, Faculty of Education Sciences, Spain.
Received Date: December 03, 2018

Published Date: December 06, 2018

\begin{abstract}
This study constitutes an experimental investigation of two groups, a group formed by 18 children diagnosed with Autism Spectrum Disorder [ASD] and a control group consisting of 20 children with typical development. A total of 38 children make up study, whose basic goal is to generate empirical evidence of Semantic Integration Dimension [SI], as soon as, constitutes a differential dimensional standard of the specific diagnosis process of ASD. The contents analysis, that develop SI Dimension, has been obtained from data found in six Sub-dimensions, quantified in five successive values, it's to the items- criteria that compose them.

Results, found by Linear Regression analysis of each dimension reflect a highly significant $\mathrm{p}$ level, which allows conclude that SI Dimension shape a differential criterion of the diagnostic process. In conclusion, it's possible set up a scale for measuring the criteria, that form SI Dimension, giving to Semantic Integration Scale [SIS], in order to complement currently existing Scales and reduce possible errors in the ASD' early detection.
\end{abstract}

Keywords: Autism spectrum disorder; Diagnosis; Semantic process

\section{Introduction}

Figure 1: Diagnosis Dimensions.




According to American Psychiatric Association International Classification [APA] [1], people with Autism Spectrum Disorder [ASD] present perceptive- cognitive limitations, that influence processing particularities, specify about deficits in dimensions of interaction, social communication and restrictive behavior, which, following three degrees, are combined throughout multiple intensity sequences. These limitations impact interrelated in the set of basic psychological parameters, whose conceptual description based on structural deficits around understanding, coding and conceptual memory or semantic understanding process [2,3] that, globally, configure processual functioning of cognitive system Figure 1.

The complexity of interactions between different ASD levels progressively practice its influence on functionality of everyday responses and actions, modifying all interactive domains, both conceptual domains, as social domain and, finally, practical domain Figure 2. So, while, conceptual domain is related to perceptivecomprehensive processes of the environment stimulation, cognitive performance adapts resulting processing way, social domain influences in way to carry out social interactions, like so, in social communication interrelated with their interlocutors and, finally, practical domain already concern to skills characteristic of life autonomy of daily life.

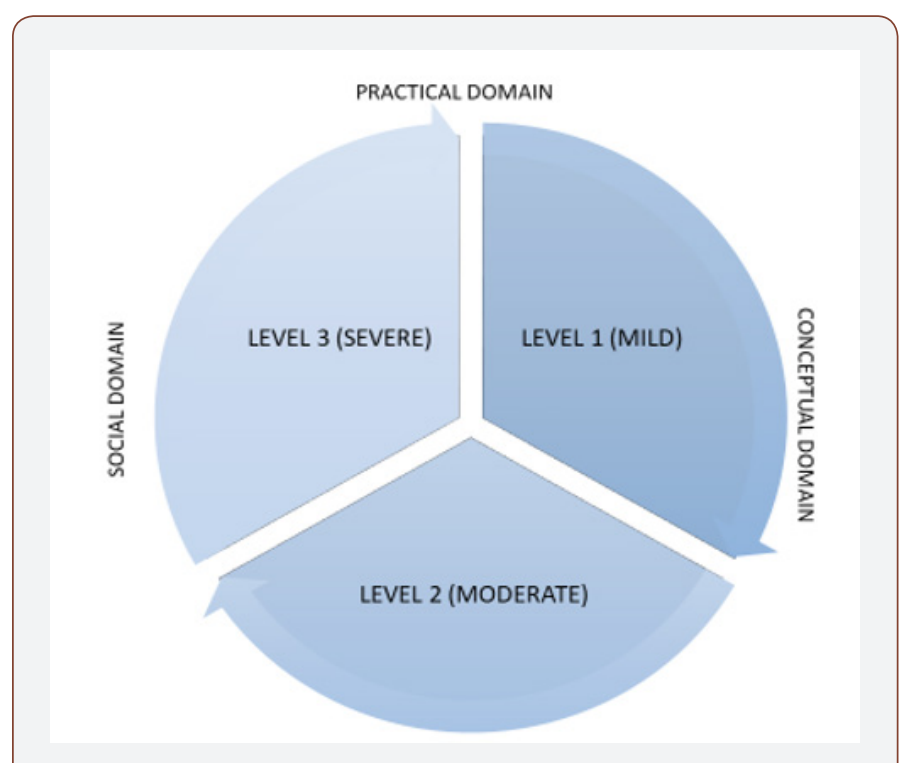

Figure 2: Functional Domains.

Indeed, for each criterial dimension, it's been possible to set each elements or symptomatic units that make it. For this reason, several diagnostic Scales have collected criteria of both dimensions, in order to specify the diagnostic processes. Thus, e. g., Autism Spectrum Inventory [ASI] [4], or Verification Checklist of the ASD' Behavior [ASDBC-R] [5], determines the specific standards of two dimensions:

I. Interaction and Social Communication Dimension: 1) social relationships, 2) joint reference abilities, 3) intersubjective and mentalists abilities, and 4) expressive and receptive communicative dimensions disorders.

II. Restricted Behaviors Dimension: 1) anticipation, 2) flexibility, 3) activity sense, 4) fiction and imagination, 5) imitation, and 5) activity suspension.
III. Now, perceptual-cognitive process is based in information' semantic understanding, which's developed from information encoded in long-term memory or semantic memory and, and, despite the criteria importance, that shapes Sematic Integration Dimension [SI], its analysis isn't specified in actual existing analyzes.

Empirical evidences of the SI Dimension importance are recurrent. Kelley E, et al. [6] carry out an investigation study, related with the linguistic singularities, to 14 children with ASD, aged 5-9 years, compared with their equals of control group and conclude that, although, scores found between the two groups, in relation to grammatical structure, it's just imperceptible, however differences in pragmatic and semantic language are highly significant, in which, students with ASD present severe limitations.

Cronin [7] also, through a study leaded with 13 children with ASD of high functioning, show that, while a relationship between oral phonological processes wasn't observed, however, relationships were significant between semantic comprehension, decoding processes and conceptual comprehensive processes, that conclude with semantic process importance in specific development levels of children with ASD.

Botting N, et al. [8] perform a comparative study between diagnostic groups with communication disorders, of which, a subgroup was formed by 6 children with ASD and another control subgroup made up of students with typical development. Results showed that children with ASD obtained a performance in pragmatic semantics tasks significantly lower the other clinical groups, both the typical development group and group with communication disorders.

Bennett TA, et al. [9], through a study conducted on associations between comprehensive language and social skills, performed with 365 children, aged 2-4 years, with and without cognitive deficits, found small cross reciprocal associations among subgroups of children with ASD with and without cognitive impairment, however, a specific pattern was found, which suggests the two domains were significantly related to the diagnostic process in preschool children with ASD and, then, seemed to become more independent throughout next 12 months of development.

Brignell A, et al. [10] analyzed retrospectively a description of oral language development predictors in verbal children 4-7 age years with ASD $(n=26-27)$, compared to a children group with typical development $(n=858-861)$ and another group with language disorders $(n=119)$. Data indicated that, first, children with ASD and language disorders showed similar results, but being both significantly lower than typical development group. However, these data confirm that, although oral evolution doesn't present significant differences, the conceptual decoding development or semantic criteria, corresponding with pragmatic language, it differed significantly.

For this reason, Kjelmer L, et al. [11], in a longitudinal study carried out over 2 years, with 208 preschool children with ASD, they highlight need for a well specified linguistic assessment, as diagnosis' basic factor. 
However, despite empirical justification, SI Dimension isn't reflected in diagnostic inventories, for this reason, this research proposed to respond the following goals:

I. Find the Sub-dimensions' differential level explanatory variations, that make up SI Dimension, as a specific characteristic of people diagnosed with ASD, compared to individuals with typical development.

II. Set up a consistent Diagnostic Scale, formed by the SI Dimension' successive items-criteria to facilitate specific evaluation of people with ASD.

\section{Method}

\section{Design}

This research design is based on experimental study of two groups, an experimental group [EG] selected by students diagnosed with ASD and a control group [CG] formed by students with typical development.

\section{Participants}

A total of 38 individuals participated in study, distributed in two groups, EG is formed by 18 children with ASD and GC was by 20 children with typical development, of ages in range of 7-15 age years, grouped into three age intervals, belonging to both sexes, whose distribution, by age and sex, can be observed in Tables $1 \& 2$.

Table 1: Group *Age Distribution.

\begin{tabular}{|c|c|c|c|c|c|}
\hline \multirow{2}{*}{} & & \multicolumn{3}{|c|}{ Age } & \multirow{2}{*}{ Total } \\
\cline { 2 - 6 } & & 7-9 years & $\begin{array}{c}10-12 \\
\text { years }\end{array}$ & $\begin{array}{c}13-15 \\
\text { years }\end{array}$ & \\
\hline \multirow{2}{*}{ Group } & EG (ASD) & 7 & 6 & 5 & 18 \\
\cline { 2 - 6 } & CG (TIPIC) & 7 & 7 & 6 & 20 \\
\hline Total & & 14 & 13 & 11 & 38 \\
\hline
\end{tabular}

Table 2: Group *Sex Distribution.

\begin{tabular}{|c|c|c|c|c|}
\hline \multirow{2}{*}{} & & \multicolumn{2}{|c|}{ Sex } & \multirow{2}{*}{ Total } \\
\cline { 2 - 5 } & & Men & Women & \\
\hline \multirow{2}{*}{ Group } & EG (ASD) & 14 & 4 & 18 \\
\cline { 2 - 5 } & CG (TIPIC) & 16 & 4 & 20 \\
\hline \multirow{2}{*}{ Total } & & 30 & 8 & 38 \\
\hline
\end{tabular}

\section{Variables}

The study' variables are following:

Group variable: formed by two groups, an EG selected by 18 students with ASD, from orientation departments reports, and a CG of 20 students with typical development. This variable makes up the Study Dependent Variable (DV), while the other variables are considered independent variables (IV).

Age variable: children 7- 15 age years, divided into three age groups (7-9 years, 10-12 years and 13- 15 years).

Sex variable: men and women.

\section{Sub-dimensions variables (SI Dimension):}

SUB-DIMENSION 1: Deficits to conceptual units understanding.
SUB-DIMENSION 2: Deficits to significant reconstruction.

SUB-DIMENSION 3: Deficits to conceptual- categories hierarchy.

SUB-DIMENSION 4: Deficits to inter- conceptual relations development (nodes).

SUB-DIMENSION 5: Deficits to setting inter- categories relationships

SUB-DIMENSION 6: Deficits to information remind.

\section{Variables values}

Sub-dimensions 1- 6 were calculated by the mean score, found from the application of Yuste C [12] MY Memory Test and the Comprehensive Language Subtest, from Childhood Neuropsychological Maturity Questionnaire [13]. Besides, in Subdimensions 2, 3, 4 and 5 was added to previous scores, the ad hoc recording of RELATEA program development activities application: 6.1 .6 (p. 81) and 6.1 .10 (p. 99) Ojea M [14], based upon in Omar E [15] structure, in order to observe skills of students in learning and use of conceptual nodes.

Each Sub-dimension is quantified in five values, which correspond to the Sub-dimensions' items- criterion:

$\rightarrow 0$ (no deficit)- 2 (mild deficit) - 4 (half deficit) -6 (severe deficit) - 8 (gave deficit).

\section{Procedure}

Study was carried out throughout academic year 2017-18. First, students corresponding to different educational schools with and without ASD' diagnosis were selected. Students with ASD attend specific treatment at a local Autism Association. Subsequently, after requested corresponding permits, Sub-dimensions' criteria were measured.

As per data found, finally, Semantic Integration Scale was validated.

\section{Data analysis}

Data were calculated from Linear Regression equation values, in order to know of the Sub-dimensions' explanatory influence differential level, in relation to group variable.

Likewise, possible influences of constant for Age and Sex variables about Group were measured.

\section{Results}

Results shows scores two types: 1) differential explanatory variance of static variables (Age and Sex). These variables don't show significant relationships about Group variable, and 2) Subdimensions' variables analysis indicates significant differential relationships between students group diagnosed with ASD and typical development group.

Table 3: Model Summary.

\begin{tabular}{|c|c|c|c|c|}
\hline Model & R & R Square & F & p. \\
\hline 1 & $.048(a)$ & .00 & .04 & $.96(\mathrm{a})$ \\
\hline
\end{tabular}

a): Predictors (Constant): Age, Sex. DV: Group. 
Thus, Linear Regression Equation constant study for Age and Sex variables may observed in Table 3 .

Table 4: Multiple Comparisons.

\begin{tabular}{|c|c|c|c|c|c|c|}
\hline \multirow[t]{2}{*}{ (I) Age } & \multirow{2}{*}{ (J) Age } & \multirow{2}{*}{ Mean Difference (I-J) } & \multirow{2}{*}{ Std. Error } & \multirow{2}{*}{ p. } & \multicolumn{2}{|c|}{ 95\% Confidence Interval } \\
\hline & & & & & Lower Bound & Upper Bound \\
\hline \multirow[t]{2}{*}{ 9-Jul } & $12-0 \mathrm{ct}$ & -0.03 & 0.2 & 0.98 & -0.52 & 0.45 \\
\hline & $13-15$ & -0.04 & 0.2 & 0.97 & -0.55 & 0.46 \\
\hline \multirow[t]{2}{*}{ 12-Oct } & 9-Jul & 0.03 & 0.2 & 0.98 & -0.45 & 0.52 \\
\hline & $13-15$ & 0 & 0.21 & 0.99 & -0.52 & 0.51 \\
\hline \multirow[t]{2}{*}{$13-15$} & 9-Jul & 0.04 & 0.2 & 0.97 & -0.46 & 0.55 \\
\hline & $12-0 \mathrm{ct}$ & 0 & 0.21 & 0.99 & -0.51 & 0.52 \\
\hline
\end{tabular}

\section{DV: Group.}

Tukey HSD

Post- Hoc comparative analysis, calculated for Age range, also, don't suggest variability' significant differences regarding differential influence about Group type variable (Table 4).

Independent Samples Test comparative analysis to Sex variable exhibit that there're no significant differences in relation to Group type.: Equal variances assumed $\mathrm{T}=.16(\mathrm{p}=.87)$, Equal Variances not assumed $\mathrm{T}=.15(\mathrm{p}=.87)$.

Linear Regression analysis to Sub-dimensions describes explanatory variance differences of each Sub-dimension about Group variable (Table 5).

Table 5: Sub-dimensions' differential analysis.

\begin{tabular}{|c|c|c|c|c|c|c|}
\hline $\begin{array}{c}\text { Sub- } \\
\text { dimensions }\end{array}$ & $\begin{array}{c}\mathbf{X}^{2} \\
\text { Pearson }\end{array}$ & $\mathbf{R}$ & $\begin{array}{c}\mathbf{R} \\
\text { Square }\end{array}$ & $\boldsymbol{\beta}$ & $\mathbf{F}$ & $\mathbf{p}$ \\
\hline $\begin{array}{c}\text { SUB- } \\
\text { DIMENSION 1 }\end{array}$ & 9.78 & .50 & .25 & .40 & 12.25 & .01 \\
\hline $\begin{array}{c}\text { SUB- } \\
\text { DIMENSION 2 }\end{array}$ & 6.10 & .40 & .16 & .37 & 6.88 & .01 \\
\hline $\begin{array}{c}\text { SUB- } \\
\text { DIMENSION 3 }\end{array}$ & 12.42 & .53 & .27 & .44 & 13.72 & .01 \\
\hline $\begin{array}{c}\text { SUB- } \\
\text { DIMENSION 4 }\end{array}$ & 7.51 & .44 & .19 & .38 & 8.84 & .00 \\
\hline $\begin{array}{c}\text { SUB- } \\
\text { DIMENSION 5 }\end{array}$ & 10.44 & .52 & .27 & .35 & 13.32 & .00 \\
\hline $\begin{array}{c}\text { SUB- } \\
\text { DIMENSION 6 }\end{array}$ & 12.83 & .46 & .21 & .26 & 9.84 & .00 \\
\hline
\end{tabular}

\section{DV: Group}

As observed, in all Sub-dimensions were found significance critical levels ( $p$ ) that, although with light differences between himself, of associated regression values, indicate a differential highly significant level about Group type: Sub-dimension $1: \mathrm{p}=.01$, Sub-dimension 2: $\mathrm{p}=.01$, Sub-dimension 3: $\mathrm{p}=.01$, Sub-dimension $4: p=.00$, Sub-dimension 5: $p=.00$ and Sub-dimension $6: p=.00$, what allows conclude the six Sub-dimensions can be considered specific differential variables of ASD diagnosis compared to group formed by students with typical development. Then, SI Dimension, which includes the six sub-dimensions constitutes an effective differential specific criterion of ASD diagnosis.
As observed, to $\mathrm{R}$ Square $=.00$ present significance level= according to assigned Group type. .96 , which indicates both variables don't influence differentially

\section{Scale}

The quantified values for six Sub-dimensions, allows to get criterion- items, which configure the Semantic Integration Scale (SIS) (Table 6).

Table 6: Semantic Integration Scale (SIS).

SUB-DIMENSION 1. Deficits to conceptual units understanding.

\begin{tabular}{|c|c|}
\hline 1.1. There's not significant conceptual units understanding. & 8 \\
\hline 1.2. There's concretion of conceptual units' parts. & 6 \\
\hline $\begin{array}{c}\text { 1.3. There's conceptual units' analysis. } \\
\text { 1.4. Conceptual units are understood, but with tendency to } \\
\text { subdivide units into its parts. }\end{array}$ & 4 \\
\hline 1.5. There's no qualitative deficit. & 0 \\
\hline
\end{tabular}

SUB-DIMENSION 2. Deficits to significant reconstruction.

\begin{tabular}{|c|c|}
\hline 2.1. There's no parts (units) reconstruction. & 8 \\
\hline 2.2. External help is need to stimulus reconstruction. & 6 \\
\hline $\begin{array}{c}\text { 2.2. Stimuli parts reconstruction is carried out with learned } \\
\text { relationships. }\end{array}$ & 4 \\
\hline $\begin{array}{c}\text { 2.4. Stimuli parts are reconstructed as from relationships } \\
\text { created. }\end{array}$ & 2 \\
\hline 2.5. There's no qualitative deficit. & 0 \\
\hline
\end{tabular}

SUB-DIMENSION 3. Deficits to conceptual- categories hierarchy.

\begin{tabular}{|c|c|}
\hline 3.1. There's no belonging understanding. & 8 \\
\hline 3.2. There's category construction is limited to some concepts. & 6 \\
\hline $\begin{array}{c}\text { 3.3. External help is need to indicate units' belonging level to } \\
\text { categories. }\end{array}$ & 4 \\
\hline $\begin{array}{c}\text { 3.4. There's awareness of belonging, but it's difficult assign an } \\
\text { unit to its category. }\end{array}$ & 2 \\
\hline $\begin{array}{c}\text { 3.5. There's tendency to concepts hierarchize in corresponding } \\
\text { category. }\end{array}$ & 0 \\
\hline
\end{tabular}


SUB-DIMENSION 4. Deficits to inter- conceptual relations development (nodes).

\begin{tabular}{|c|c|}
\hline $\begin{array}{l}\text { 4.1. No competences of relationships meaning between } \\
\text { concepts. }\end{array}$ & 8 \\
\hline $\begin{array}{l}\text { 4.2. Don't creates relationships but understands similarities and } \\
\text { differences between concepts. }\end{array}$ & 6 \\
\hline $\begin{array}{l}\text { 4.3. External help is needed to create relationships among } \\
\text { concepts. }\end{array}$ & 4 \\
\hline $\begin{array}{l}\text { 4.4. Relationships are used between two concepts if its're } \\
\text { previously learned. }\end{array}$ & 2 \\
\hline $\begin{array}{l}\text { 4.5. There's no limitations to form relationships between two } \\
\text { new concepts. }\end{array}$ & 0 \\
\hline \multicolumn{2}{|l|}{ SUB-DIMENSION 5. Deficits to setting inter- categories relationship } \\
\hline $\begin{array}{l}\text { 5.1. There's no understanding relationship between conceptual } \\
\text { categories. }\end{array}$ & 8 \\
\hline $\begin{array}{l}\text { 5.2. Two different conceptual categories are understood, but it's } \\
\text { not able to attribute relationships. }\end{array}$ & 6 \\
\hline 5.3. External help is required to establish relationships. & 4 \\
\hline $\begin{array}{l}\text { 5.4. It's given learned relationships to different conceptual } \\
\text { categories. }\end{array}$ & 2 \\
\hline $\begin{array}{l}\text { 5.5. Relationships are created between different conceptual } \\
\text { categories. }\end{array}$ & 0 \\
\hline
\end{tabular}

SUB-DIMENSION 6. Deficits to information remind.

\begin{tabular}{|c|c|}
\hline 6.1. There's information recovery, but it's very limited. & 8 \\
\hline 6.2. External help is needed to facilitate information retrieval. & 6 \\
\hline 6.3. There's information recovery, but from concrete concept. & 4 \\
\hline 6.4. There's information recovery, from learned relationship. & 2 \\
\hline 6.5. There's no qualitative deficit. & 0 \\
\hline
\end{tabular}

The total score is assigned, through observation of criterionstandard valued, giving intermediate valuations between numerical groups and its decimals. Thus, e.g., for numeric group (0-2), evaluation may include: $0.5-1-1.5-2$, and so on.

The Scale correction data is calculating the sum of results obtained in each clinical study, moved to percentage score= $\mathrm{X} / 48^{*} 100$, being $\mathrm{X}$ score obtained during assessment. Subdimension correction data is through specific rule $=X / 8^{*} 100$, being $\mathrm{X}$ score obtained throughout person assessment.

\section{Conclusion}

SI Dimension, configured based upon in semantic coding of information, is, therefore, specific nuclear criterial element to facilitate diagnosis' effectiveness, in order to complement diagnosis analysis, under the heterogeneity model, to facilitate reduction of basic errors in initial evaluation processes, above all, when this analysis is carried out at early age.

For this reason, study includes the SI Dimension as a differential diagnosis factor after the two APA' [1] Dimensions (Table 7).
Table 7: ASD conceptual review.

\begin{tabular}{|c|c|c|c|}
\hline \multirow[t]{2}{*}{ Levels } & \multicolumn{3}{|c|}{ Dimensions } \\
\hline & $\begin{array}{c}\text { I) } \\
\text { Communication } \\
\text { and Social } \\
\text { Interaction }\end{array}$ & $\begin{array}{l}\text { Ii) Restricted } \\
\text { Interests and } \\
\text { Repetitive } \\
\text { Behavior }\end{array}$ & $\begin{array}{l}\text { Iii) Semantic } \\
\text { Integration }\end{array}$ \\
\hline 3 & $\begin{array}{l}\text { Severe deficits } \\
\text { in verbal social } \\
\text { communication. }\end{array}$ & $\begin{array}{l}\text { Excessive worry, } \\
\text { fixed rituals, that } \\
\text { interfere heavily } \\
\text { into behavior. }\end{array}$ & $\begin{array}{c}\text { Analysis of } \\
\text { concept parts. }\end{array}$ \\
\hline 2 & $\begin{array}{c}\text { Deficits in } \\
\text { social and } \\
\text { communication } \\
\text { skills. }\end{array}$ & $\begin{array}{l}\text { Rituals that } \\
\text { interfere } \\
\text { often in social } \\
\text { functioning. }\end{array}$ & $\begin{array}{c}\text { Concepts' } \\
\text { partial analysis, } \\
\text { with a tendency } \\
\text { to establish } \\
\text { meanings. }\end{array}$ \\
\hline 1 & $\begin{array}{l}\text { Communication } \\
\text { deficits. }\end{array}$ & $\begin{array}{l}\text { Rituals that cause } \\
\text { interference } \\
\text { in one or more } \\
\text { social contexts. }\end{array}$ & $\begin{array}{l}\text { Analysis with } \\
\text { meaning of } \\
\text { concepts, with } \\
\text { difficulties } \\
\text { for their } \\
\text { categorization. } \\
\text { Limitations to } \\
\text { set up inter- } \\
\text { categories } \\
\text { relationships. }\end{array}$ \\
\hline
\end{tabular}

Source: own elaboration, from American Psychiatric Association [APA] [1].

Thus, IDEA test [4] or ASDBC-R Scale [5] can be enriched with the issues proposed by SIS Scale, since it facilitates standards understanding relating to SIS Dimension, integrated in perceptualcognitive analysis interactively, as well as it's possible to indicate the subsequent treatment.

\section{Discussion}

Indeed, ASD' heterogeneity characteristic constitute an essential element of diagnostic process, therefore, unique and inflexible tools can favor diagnostic errors, so empirical evidence must consider diagnosis heterogeneity to ensure a comprehensive assessment of all children suspected of having ASD, with quality and success assurance through process.

Penner M, et al. [16] carried out an exhaustive analysis of diagnostic processes and its implications for practice, both referred to quality, as to content of 839 documents. Resulting data indicate presence of important inconsistencies in diagnostic documents analyzed, both in relation to evaluation aspects and based on the diagnosis instruments used, showing a low rigor and certain lack of evidence in quality of this.

Probably, these deficiencies may be due to lack of available empirical evidence, relating to different components that lead to disorder systematic evaluation, so, to compensate current empirical evidence absence, Graham B, et al. [17] propose, precisely, use of Delphi which, is both diagnosis process and integrated intervention method.

However, it's essential to deep into empirical evidence of instruments for the semantic processes analysis, in order to place with effectiveness spectrum level, as well as facilitate basic goals for adapted intervention, to improve language pragmatic components. Adams C, et al. [18] just promote a program to develop semantic- 
pragmatic language in people with ASD, through procedure Bishop's ALICC [19,20], whose results showed of the adjusted treatment importance, since are related and significantly associated with skills and general processing, which implies a comprehensive improvement at global development level in people with ASD. Study concluded with a set of recommendations for future research, study concluded with a series of recommendations for future research, among which, the following stand out: 1) comprehensively measure pragmatic and semantic skills, 2) enhance development of pragmatic language processes as a constant goal of specific intervention and, 3) facilitate active participation of families, teachers and professionals throughout whole process.

\section{Study Limitations}

This study is limited by small number of cases analyzed, which is usual in research with groups with special educational needs, so it's necessary to continue empirical analysis in order deepen into development of specific evaluation measures, related with specific perceptive- cognitive processing.

\section{Acknowledgement}

Our thanks in study development to TRASCOS Autism Association and to participating orientation departments.

\section{Conflict of Interest}

No conflict of interest.

\section{References}

1. American Psychiatric Association (APA) (2013) Diagnostic and Statistical Manual of Mental Disorders (DSM-5). Arlington, VA

2. (2007) Children's comprehension problems in oral and written language: A cognitive perspective. In: Cain K, Oakhill J (Eds). Challenges in language and literacy. New York, USA, pp. 1-302.

3. Stothers ME, Cardy J Oram (2012) Oral language impairments in developmental disorders characterized by language strengths: A comparison of Asperger Syndrome and Nonverbal Learning Disabilities. Research in Autism Spectrum Disorders 6(1): 519-534.

4. Rivière A (2002) ASI: Autistic Spectrum Inventory. FacatativáCundinamarca: Fundec.

5. Bitsika V, Sharpley CF (2018) Making the transition from diagnosis to treatment-planning: validity, reliability and factor structure of the Autism Spectrum Disorder behavior checklist. International Journal of Disability, Development and Education 65(1): 22-32.
6. Kelley E, Paul JJ, Fein D, Naigles LR (2006) Residual language deficits in optimal outcome children with a history of Autism. J Autism Dev Disord 36(6): 807-828.

7. Cronin KA (2014) The relationship among oral language, decoding skills, and reading comprehension in children with Autism. Exceptionality 22(3): 141-157.

8. Botting N, Adams C (2005) Semantic and inferencing abilities in children with communication disorders. Int J Lang Commun Disord 40(1): 49-66.

9. Bennett TA, Szatmari P, Georgiades K, Hanna S, Janus M, et al. (2015) Do reciprocal associations exist between social and language pathways in pre-schoolers with Autism Spectrum Disorders? J Child Psychol Psychiatry 56(8): 874-883.

10. Brignell A, Williams K, Jachno K, Prior M, Reilly S, et al. (2018) Patterns and predictors of language development from 4 to 7 years in verbal children with and without Autism Spectrum Disorder. J Autism Dev Disord 48(10): 3282-3295.

11. Kjellmer L, Hedvall A, Holm A, Fernell E, Gillberg C, et al. (2012) Language comprehension in pre-schoolers with Autism Spectrum Disorders without Intellectual Disability: Use of the Reynell Developmental Language Scales. Research in Autism Spectrum Disorders 6(3): 11191125.

12. Yuste C (2005) MY. Memory Test. Madrid: TEA.

13. Portellano JA, Mateos R, Martínez R, Granados MJ, Tapia A (2002) Childhood Neuropsychological Maturity Questionnaire. Madrid: TEA.

14. Ojea M (2018) RELATEA Program. Conceptual categories development in students with autism spectrum disorders. Madrid: Pirámide.

15. Omar E (2015) Semantic image pairing test: Instructions and guidelines for analysis of its execution. Revista Cubana de Neurología y Neurocirugía 5(1): S30-S37

16. Penner M, Anagnostou E, Andoni LY, Ungar WJ (2018) Systematic review of clinical guidance documents for Autism Spectrum Disorder, diagnostic assessment in select regions. Autism 22(5): 517-527.

17. Graham B, Reghr G, Wright JG (2003) Delphi as a method to establish consensus for diagnostic criteria. J Clin Epidemiol 56(12): 1150-1156.

18. Adams C, Lloyd J, Aldred C, Baxendale J (2006) Exploring the effects of communication intervention for developmental pragmatic language impairments: A signal- generation study. Int J Lang Commun Disord 41(1): 41-65.

19. Bishop DVM (2000) Pragmatic language impairment: A correlate of SLI, a distinct subgroup, or part of the autistic continuum? In: DVM Bishop, L Leonard (Eds.), Speech and language impairments in children: Causes, characteristics, intervention and outcome. Hove, Psychology Press, UK, pp. 99-114.

20. Bishop DVM (2003) The children's communication checklist (CCC-2). London, Harcourt. 